\title{
The Q15H mutation enables Crh, a Bacillus subtilis HPr-like protein, to carry out some regulatory HPr functions, but does not make it an effective phosphocarrier for sugar transport
}

\author{
Isabelle Martin-Verstraete, ${ }^{1} \dagger$ Anne Galinier, ${ }^{2}$ Emmanuelle Darbon, ${ }^{3}$ \\ Yves Quentin, ${ }^{4}$ Marie-Claude Kilhoffer, ${ }^{5}$ Véronique Charrier, ${ }^{2} \neq$ \\ Jacques Haiech, ${ }^{5}$ Georges Rapoport ${ }^{1}$ and Josef Deutscher ${ }^{3}$
}

Author for correspondence: Josef Deutscher. Tel: +331308154 47. Fax: +33130815457. e-mail: jdeu@platon.grignon.inra.fr

1 Unité de Biochimie Microbienne, CNRS URA 1300, Institut Pasteur, F-75724 Paris, France

2 Institut de Biologie et Chimie des Protéines, CNRS UPR 412, F-69367 Lyon Cedex 07, France

3 Laboratoire de Génétique des Microorganismes, INRA-CNRS URA 1925, F-78850 Thiverval-Grignon, France

4 Laboratoire de Chimie Bactérienne, CNRS UPR 9043, F-13009 Marseille, France

5 Laboratoire de Biophysique, URA 491, Université Louis Pasteur, F-67401 Illkirch Cedex France
Crh of Bacillus subtilis exhibits $\mathbf{4 5} \%$ sequence identity when compared to histidine-containing protein (HPr), a phosphocarrier protein of the phosphoenolpyruvate (PEP) : sugar phosphotransferase system (PTS). Crh can be phosphorylated by ATP at the regulatory Ser-46 and similar to P-Ser-HPr, P-Ser-Crh plays a role in carbon-catabolite repression. The sequence around the phosphorylatable Ser-46 in Crh exhibits strong similarity to the corresponding sequence of HPr of Gram-positive and a few Gram-negative bacteria. In contrast, the catalytic His-15, the site of PEP-dependent phosphorylation in $\mathrm{HPr}$, is replaced with a glutamine in Crh. When Gln-15 was exchanged for a histidyl residue, in vitro PEP-dependent enzyme I-catalysed phosphorylation of the mutant Crh was observed. However, expression of the crhQ15H mutant allele did not restore growth of a ptsH deletion strain on the PTS sugars glucose, fructose or mannitol or on the non-PTS sugar glycerol. In contrast, Q15H mutant Crh could phosphorylate the transcriptional activator LevR as well as LevD, the enzyme IIA of the fructose-specific lev-PTS, which together with enzyme I, HPr and LevE forms the phosphorylation cascade regulating induction of the lev operon via LevR. As a consequence, the constitutive expression from the lev promoter observed in a $\Delta p t s H$ strain became inducible with fructose when the crhQ15H allele was expressed in this strain.

Keywords: PEP:sugar phosphotransferase system, HPr, Crh, catabolite repression

\section{INTRODUCTION}

The histidine-containing protein $(\mathrm{HPr})$ is a phosphocarrier protein which plays a central role in the uptake of carbohydrates via the phosphoenolpyruvate (PEP): sugar phosphotransferase system (PTS) (for a review, see Postma et al., 1993). It is phosphorylated by the PEPdependent protein kinase enzyme I at His-15 and transfers the phosphoryl group to several enzymes IIA,

\footnotetext{
Present address: Unité de Régulation de l'Expression Génétique, CNRS URA 1129, Institut Pasteur, F-75724 Paris, France.

‡Present address: Dept of Biochemistry, The Bowman Gray School of Medicine, Wake Forest University, Winston-Salem, NC 27157-1016, USA.

Abbreviations: $\mathrm{FPr}$, fructose-specific $\mathrm{HPr}$; $\mathrm{HPr}$, histidine-containing protein; NPr, nitrogen-related HPr; PEP, phosphoenolpyruvate; PTS, PEP:sugar phosphotransferase system.
}

each specific for a certain carbohydrate. The phosphorylated enzymes IIA phosphorylate their corresponding enzyme IIB, which finally transfers the phosphoryl group to the carbohydrate bound to the membrane-spanning enzyme IIC. The enzymes II either can form a single protein with three domains (A, B and C) or can be split into two to four distinct proteins (Saier \& Reizer, 1992). HPr of Gram-positive bacteria is also phosphorylated by the metabolite-activated ATP-dependent HPr kinase at Ser-46 (Deutscher \& Saier, 1983; Galinier et al., 1998; Reizer et al., 1998). HPr kinase is a bifunctional enzyme that also catalyses dephosphorylation of P-Ser-HPr (Kravanja et al., 1999). P-Ser-HPr functions as corepressor in carbon-catabolite repression by interacting with the catabolite control protein A (CcpA) (Deutscher et al., 1995), a member of the LacI/GalR family of repressors (Henkin et al., 1991). 
The complex between P-Ser-HPr and CcpA binds to the catabolite response element (cre) (Fujita et al., 1995; Gösseringer et al., 1997; Kim et al., 1998; Galinier et al., 1999; Martin-Verstraete et al., 1999), an operator-like sequence present in most catabolite-repressed genes and operons (Hueck et al., 1994).

Most bacteria possess only one $p t s I$ and one $p t s H$ gene encoding the general PTS components enzyme I and $\mathrm{HPr}$, respectively. In Bacillus subtilis, the general PTS components participate in sugar transport and phosphorylation via the approximately 15 different sugar-specific enzymes II detected within the genome sequencing programme (Kunst et al., 1997). However, a few Gram-negative bacteria possess more than one enzyme I or HPr. Escherichia coli and Salmonella typhimurium, for example, contain a fructose-inducible diphosphoryl transfer protein which is composed of an $\mathrm{N}$-terminal enzyme IIA ${ }^{\text {Fru }}$ and a C-terminal HPr-like domain (Waygood et al., 1984; Geerse et al., 1989) called FPr (fructose-specific HPr). The diphosphoryl transfer protein is phosphorylated by enzyme I at the HPr-like domain from where the phosphoryl group is subsequently transferred to the enzyme IIA ${ }^{\text {Fru }}$ domain. Interestingly, Haemophilus influenzae was found to possess a protein composed of an N-terminal enzyme IIA $^{\text {Fru }}$ domain and two FPr domains fused in tandem to the $\mathrm{C}$-terminus. This protein was also suggested to be active in fructose transport, but no specific function was attributed to the second FPr domain (Reizer et al., 1996).

Evidence for PTS-mediated regulation of nitrogen assimilation and fixation was provided by the finding that in several Gram-negative bacteria the two genes $p t s \mathrm{~N}$ and $p t s \mathrm{O}$, which encode an enzyme IIA ${ }^{\mathrm{Fru}}$ - and an $\mathrm{HPr}-$ like protein, respectively, were located in the vicinity of the rpoN gene (Reizer et al., 1992a; Jones et al., 1994). The rpoN gene encodes the alternate sigma factor $\sigma^{54}$, which is necessary for transcription of genes required for nitrogen assimilation and fixation, and $\sigma^{54}$ was thought to be regulated by PtsN and PtsO. These two proteins were therefore renamed enzyme IIA ${ }^{\mathrm{Ntr}}$ and NPr (for nitrogen-related HPr), respectively. Enzyme IIA ${ }^{\text {Ntr }}$ and NPr were found to exchange phosphate with enzyme I, HPr and enzyme IIA of the PTS (Powell et al., 1995). Loss of enzyme IIA $^{\mathrm{Ntr}}$ activity diminished carboncatabolite repression of $\sigma^{54}$-dependent transcription of the Pseudomonas putida $x y l S$ operon when expressed in E. coli (Du et al., 1996).

Neither FPr nor NPr were detected in B. subtilis (Kunst et al., 1997). Nevertheless, B. subtilis was found to possess a protein exhibiting $45 \%$ sequence identity to HPr. It contained the phosphorylatable Ser-46, but the catalytic His-15 was replaced with a glutamine (Galinier et al., 1997). As a consequence, no PEP-dependent, enzyme I-catalysed phosphorylation of this protein could be detected (Galinier et al., 1997). However, the HPr-like protein can be phosphorylated by the ATPdependent HPr kinase at Ser-46 (Galinier et al., 1997). Similar to P-Ser-HPr, the seryl-phosphorylated HPr-like protein seems to interact with CcpA and to participate in catabolite activation of the ackA gene (Turinsky et al., 1998) and in catabolite repression of the B. subtilis lev, xyn and iol operons (Galinier et al., 1997, 1999; Martin-Verstraete et al., 1999) as well as the acs A gene (Zalieckas et al., 1998). It was therefore called Crh (for catabolite repression HPr). By replacing Gln-15 of Crh with a histidine we wanted to study to what extent this mutation will enable Crh to carry out the catalytic and regulatory functions of P-His-HPr.

\section{METHODS}

Bacterial strains, growth conditions, transformation procedures and phenotypic characterization. B. subtilis strain GM1341 carries an in-frame deletion of codons 7-42 of $p t s H$ (DraI/HpaI excision, called $p t s H \Delta \mathrm{DH}$ ) (Tortosa et al., 1997). Strains CRH168 and HC1341 were obtained by insertional inactivation of the crh gene of either B. subtilis wild-type strain 168 or the $p t s H$ deletion strain GM1341 using plasmid pMTcrh1. Transformation with this plasmid, derived from the vector pMUTIN1 (Vagner et al., 1998), leads to selective disruption of $c r h$ after a single recombination event with the bacterial chromosome. Chromosomal integration of a single copy of pMTcrh1 and its insertion into $c r h$ was confirmed by PCR. Strain QB7111 was obtained by co-transformation of strain 168 with chromosomal DNA from strain QB5030 carrying a $s a c C^{\prime}:$ : lacZ erm fusion (Martin-Verstraete et al., 1990) and from strain GM1341 containing the ptsH deletion. Erythromycin-resistant transformants were selected and subsequently tested for constitutive expression of the $s a c C^{\prime}:: l a c Z$ fusion. Constitutive expression from the lev promoter suggested the presence of the internal $p t s H$ deletion $p t s H \Delta \mathrm{DH}$, which was confirmed by PCR. Strain QB7114 was obtained by integrating the $c r h Q 15 H$ allele into amyE of strain QB7111 containing a sac $C^{\prime}:$ lacZ fusion and the $p t s H$ deletion ptsH $\Delta \mathrm{DH}$. E. coli TG1 [K-12 $\Delta$ (lac-pro) supE thi hsd5/F' traD36 proA $A^{+} B^{+}$lacl $^{\alpha}$ lacZ $\left.\Delta \mathrm{M} 15\right]$ was used for cloning experiments, E. coli CJ236 [dut ung thi relA/pJC105 $\left.\left(\mathrm{Cm}^{\mathrm{R}}\right)\right]$ for site-directed mutagenesis of crh and E. coli BL21(DE3) (Novagen) and M15(pREP4) (Qiagen) for overproduction of proteins. E. coli strains were grown in LB medium and $B$. subtilis in SP or C minimal medium. CSK medium is C minimal medium supplemented with potassium succinate $(6 \mathrm{~g}$ $\left.\mathrm{l}^{-1}\right)$ and potassium glutamate $\left(8 \mathrm{~g} \mathrm{l}^{-1}\right)$ (Martin-Verstraete et al., 1990).

Standard procedures were used to transform E. coli and $B$. subtilis strains (Sambrook et al., 1989; Kunst \& Rapoport, 1995). Transformants were selected on agar plates containing ampicillin $\left(100 \mu \mathrm{g} \mathrm{ml}^{-1}\right)$, erythromycin $\left(1 \mu \mathrm{g} \mathrm{ml}^{-1}\right)$ plus lincomycin $\left(25 \mu \mathrm{g} \mathrm{ml}^{-1}\right)$ or chloramphenicol $\left(5 \mu \mathrm{g} \mathrm{ml}^{-1}\right)$. $\beta$-Galactosidase activities were measured after growth of $B$. subtilis strains in CSK medium with or without $0 \cdot 2 \%$ fructose using the method of Miller (1972). One unit of $\beta$-galactosidase activity is defined as the amount of enzyme that produces $1 \mathrm{nmol}$ of $o$-nitrophenol per min at $28^{\circ} \mathrm{C}$. Doubling times were determined by growing the bacteria in $\mathrm{C}$ minimal medium supplemented with glucose, fructose, mannitol, glycerol or glucitol (each at a concentration of $0.5 \%$ ).

Plasmid constructions. Plasmid pMTcrh1 was obtained by cloning a fragment of $c r h$ into the vector pMUTIN1 (Vagner et al., 1998) cut with HindIII and BamHI. The crh fragment was obtained by PCR using chromosomal DNA from $B$. subtilis strain 168 as template and the following two primers: CCCAAGCTTCGATTAAAGACAGGACTGCAAGCACG 
and CGCGGATCCGAACGTAAGCAGCAGCTTCTCC. The non-complementary HindIII and BamHI restriction sites are indicated in bold. A $1 \mathrm{~kb}$ DNA fragment of plasmid pRC12 containing the crh gene was cloned into M13mp19 to give M13mp19crh (Galinier et al., 1997). The Muta-Gene M13 in vitro mutagenesis kit (Bio-Rad) was used to obtain the crhQ15H allele. A 434 bp PvuII-BstBI DNA fragment containing the promoterless $c r h$ gene or $c r h Q 15 H$ allele was inserted into pDR67 (Ireton et al., 1993) cut with SmaI and ClaI to give plasmid pRC16 or pRC18, respectively. Plasmid pDR67 carries the pC194 chloramphenicol acetyltransferase gene cat and a spac promoter between two fragments of the $B$. subtilis amyE gene. The crh and crhQ15H alleles were integrated downstream of the spac promoter allowing induction of their expression with $1 \mathrm{mM}$ IPTG after single-copy integration at the amyE locus of the B. subtilis genome. Appropriate oligonucleotides and pRC16 or pRC18 were used to amplify a DNA fragment carrying the $c r h$ or $c r h Q 15 H$ alleles containing the spac promoter and a BamHI site introduced $85 \mathrm{bp}$ downstream of the $\mathrm{crh}$ stop codon. These fragments were integrated into plasmid pHT315 cut with EcoRI/BamHI giving plasmids pRC19 (wild-type $c r h$ ) and pRC20 (crhQ15H), respectively. A 285 bp fragment containing the $c r h Q 15 H$ gene was amplified by PCR using RF M13mp19crhQ15H as template and two oligonucleotides creating an NdeI and a PstI restriction site at the $5^{\prime}$ and $3^{\prime}$ end, respectively. The NdeI-Pst I fragment was cloned into the expression vector pT7-7 $(6 \times$ His) (Cortay et al., 1994). The mutant protein CrhQ15H carrying a polyhistidine fused to the C-terminus was expressed from the resulting plasmid pAG6 after transformation in the E. coli strain BL21(DE3) (Novagen).

Plasmids pAG1, pAG2, pAG3, pQE30D and pQE30E, which were used for overproducing His-tagged Crh (His-tag attached to the $\mathrm{C}$-terminus), $\mathrm{HPr}$ (His-tag added to the N-terminus), enzyme I, LevD and LevE, respectively, have been described previously (Galinier et al., 1997; Charrier et al., 1997a). Transformants carrying one of the above plasmids were grown at $37^{\circ} \mathrm{C}$ in $2 \times \mathrm{TY}$ medium until the culture had reached an $\mathrm{OD}_{595}$ of $0 \cdot 7$. Expression of the genes encoding Crh, HPr, enzyme I, LevD or LevE was induced by adding IPTG to a final concentration of $1 \mathrm{mM}$, and incubation was continued for a further $4 \mathrm{~h}$. Enzyme $\mathrm{I}(\mathrm{His})_{6}, \mathrm{Crh}(\mathrm{His})_{6}$ and $\mathrm{H} \operatorname{Pr}(\mathrm{His})_{6}$ (Galinier et al., 1997) as well as $\operatorname{LevD}(\mathrm{His})_{6}$ and LevE(His) ${ }_{6}$ (Charrier et al., 1997a) were purified on Ni-NTAagarose columns.

Two-dimensional gel electrophoresis. B. subtilis cells were disrupted by adding a solubilization solution containing $8 \mathrm{M}$ urea, $4 \%$ CHAPS and $65 \mathrm{mM}$ dithioerythritol to a cell suspension and by sonicating the cells three times for $20 \mathrm{~s}$ (Branson sonifier 450 equipped with a cuphorn). The volume of the added solubilization solution exceeded the volume of the cell suspension at least threefold. Aliquots of solubilized cells containing between 30 and $40 \mu \mathrm{g}$ protein were used per silver-stained two-dimensional gel. Two-dimensional gel electrophoresis was performed using a commercially available immobilized $\mathrm{pH}$ gradient (IPG from Pharmacia Biotech) for the first dimension according to the method described on the web server (http://www.expasy.ch/ch2d/protocols.fm2.ht$\mathrm{ml}$ \#998745). The voltage was increased stepwise from $100 \mathrm{~V}$ to $3900 \mathrm{~V}$ over a period of $4 \mathrm{~h}$ and then maintained at $3900 \mathrm{~V}$ until a total of $150 \mathrm{kVh}$ was reached. The temperature was maintained at $20^{\circ} \mathrm{C}$. The IPG strips were then equilibrated and transferred to a slab gel containing a $12-20 \%$ polyacrylamide gradient, a 4-6\% glycerol gradient and $0 \cdot 1 \%$ SDS, and the electrophoresis was performed at $70 \mathrm{~V}$ overnight. Gels were silver stained using the Protein Silver Staining Kit from Pharmacia Biotech. The HPr migration position in the total cellular extract was first determined by comparison to the migration position of purified HPr (without His-tag). In the two-dimensional gels with the B. subtilis mutants GM1341 and CRH168, Crh and HPr were also identified by mass spectrometry of tryptic fragments generated by digestion of the proteins present in the corresponding spots cut out of the gel.

Protein phosphorylation assays. Phosphorylation assays with $\left[{ }^{32} \mathrm{P}\right] \mathrm{PEP}$, enzyme I(His) ${ }_{6}$ and $\mathrm{Crh}(\mathrm{His})_{6}$, $\mathrm{CrhQ15H}(\mathrm{His})_{6}$ or $\mathrm{H} \operatorname{Pr}(\mathrm{His})_{6}$ were carried out in a total volume of $20 \mu \mathrm{l}$. Oneand-a-half micrograms of $\mathrm{Crh}(\mathrm{His})_{6}$, $\mathrm{CrhQ} 15 \mathrm{H}(\mathrm{His})_{6}$ or $\mathrm{H} \operatorname{Pr}(\mathrm{His})_{6}$ was incubated for $10 \mathrm{~min}$ at $37^{\circ} \mathrm{C}$ with $2 \mu \mathrm{g}$ enzyme $\mathrm{I}(\mathrm{His})_{6}$ in $50 \mathrm{mM}$ Tris/ $\mathrm{HCl}, \mathrm{pH} 7 \cdot 4,15 \mathrm{mM} \mathrm{MgCl}_{2}$ and $10 \mu \mathrm{M}$ $\left[{ }^{32} \mathrm{P}\right]$ PEP $\left.(0.5 \mu \mathrm{Ci} ; 18.5 \mathrm{kBq}) .{ }^{32} \mathrm{P}\right] \mathrm{PEP}$ was prepared from $[\gamma-$ $\left.{ }^{32} \mathrm{P}\right]$ ATP (Roossien et al., 1983). LevR was phosphorylated with $\left[{ }^{32} \mathrm{P}\right] \mathrm{PEP}$, enzyme I(His) ${ }_{6}$ and $\mathrm{HPr}(\mathrm{His})_{6}$, $\mathrm{Crh}(\mathrm{His})_{6}$ or CrhQ15H(His) ${ }_{6}$ as described previously (Martin-Verstraete et al., 1998).

Phosphorylation of LevD and LevE was carried out by incubating a reaction mixture containing $0.2 \mu \mathrm{g}$ enzyme $\mathrm{I}(\mathrm{His})_{6}, 0.5 \mu \mathrm{g} \operatorname{LevD}(\mathrm{His})_{6}, 5 \mu \mathrm{g} \mathrm{LevE}(\mathrm{His})_{6}, 12.5 \mathrm{mM} \mathrm{MgCl}_{2}$, $50 \mathrm{mM}$ Tris/ $\mathrm{HCl}(\mathrm{pH} 7 \cdot 4), 10 \mu \mathrm{M}\left[{ }^{32} \mathrm{P}\right] \mathrm{PEP}(0.5 \mu \mathrm{Ci})$ and $0 \cdot 1 \mu \mathrm{g}$ either $\mathrm{HPr}(\mathrm{His})_{6}$ or $\mathrm{Crh}(\mathrm{His})_{6}$ for $20 \mathrm{~min}$ at $37^{\circ} \mathrm{C}$ in a total volume of $20 \mu \mathrm{l}$ (Charrier et al., 1997a). All phosphorylation reactions were stopped by adding an equal volume of sample buffer (Laemmli, 1970) to the assay mixture. Proteins were separated by SDS-PAGE. Gels were dried for $2 \mathrm{~h}$ without prior fixation or coloration and exposed to X-ray film (Biomax MR, Kodak).

\section{RESULTS}

\section{Sequence alignment of Crh with HPr from Gram- negative and Gram-positive bacteria}

The amino acid sequence of Crh was compared to different $\mathrm{HPr}, \mathrm{FPr}, \mathrm{NPr}$ and multiphosphoryl transfer proteins, and to several putative HPrs, the sequences of which were derived from complete or incomplete microbial genome sequences (Fig. 1). The region around the PEP-dependent phosphorylation site His-15 (corresponds to Gln-15 in Crh) is similar in HPr from both Gram-positive and Gram-negative bacteria and only a few amino acids were found to be present exclusively or primarily in $\mathrm{HPr}$ of either Gram-positive (Thr-12, Leu21 and Gln-24) or Gram-negative bacteria (Leu-14, Ala20 and Phe-22) (see Fig. 1). Crh seems to contain the characteristics of the PEP-dependent HPr phosphorylation site from both phylogenetically distinct groups. In contrast, the region around the ATP-dependent phosphorylation site Ser-46 in Crh exhibited much stronger similarity to the corresponding region in HPrs from Gram-positive bacteria. The previously proposed consensus sequence for the ATP-dependent phosphorylation site in $\mathrm{HPr}$ of Gram-positive bacteria $(\mathrm{V} / \mathrm{G})(\mathrm{N} / \mathrm{D}) \mathrm{XKS}(\mathrm{L} / \mathrm{I})(\mathrm{M} / \mathrm{I})(\mathrm{G} / \mathrm{N})(\mathrm{V} / \mathrm{L})(\mathrm{M} / \mathrm{L}) \quad$ Galinier et al., 1998) is in full agreement with the corresponding sequence from position 42 to 51 in $\mathrm{Crh}$. However, this consensus sequence has also been found in $\mathrm{HPr}$ of a few Gram-negative bacteria such as Alcaligenes eutrophus, Bordetella pertussis, Chloro- 
PTHP MYCCA

PTHP MYCPN

PTHP STRMU

PTHP STACA

PTHP LACSK

PTHP LISMO

PTHP ENTEA

PTHP BACST

PTHP BACSU

Crh

T pallidum

$N$ gonorrhoeae

$N$ meningitidis

$C$ cresentus2

$B$ pertussis

PTHP ALCEU

$C$ tepidum

$P$ aeruginosa

$C$ cresentus1

$C$ acetobutylicum

PTHP HAEIN

PTHP ECOLI

PTFA ECOLI

PTFA HAEI 1

PTFA HAEI2

PTSO ECOLI

PTE1 RHOCA

PTE1 XANCP

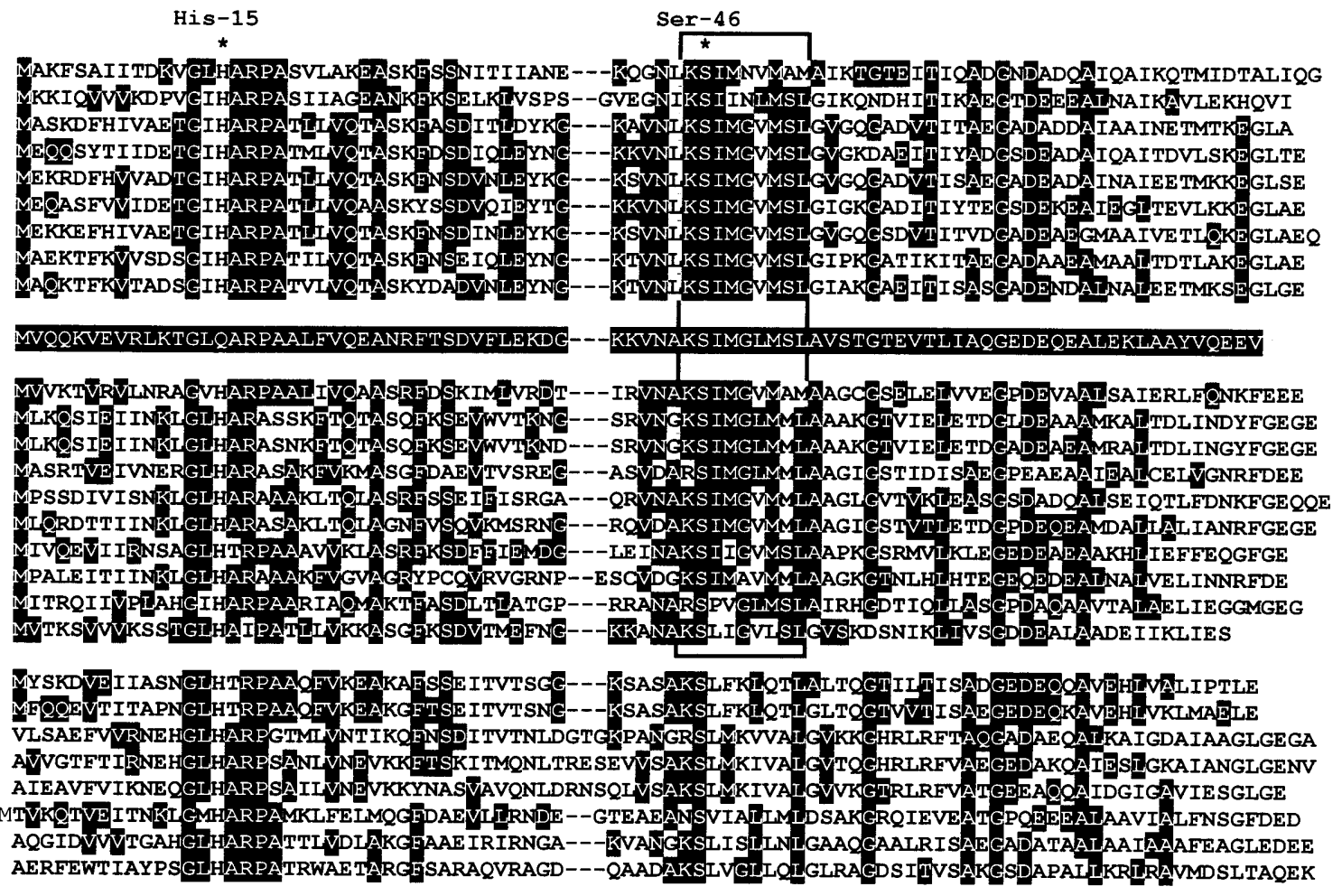

Fig. 1. Alignment of proteins related to Crh. The multiple alignment was carried out by using the CLUSTAL W program included in the sequence editor SEAVIEW (Galtier et al., 1996). The shading of the multiple alignment has been done with BOXSHADE (K. Hofmann \& M. D. Baron, unpublished). Residues in the HPr proteins that are identical to the corresponding residue in the Crh sequence are highlighted in black. The sequence KSIMGLMSL present in Crh from position 45 to 53 , which is well-conserved in HPrs and has been shown, or is assumed, to be phosphorylated at Ser-46, is boxed. The following protein sequences were extracted from SWISS-PROT (very similar sequences, such as those from $E$. coli and $S$. typhimurium, are represented by only one entry). HPr family: HPr from B. subtilis (PTHP_BACSU), B. stearothermophilus (PTHP_BACST), Lactobacillus sakei (PTHP_LACSK), Listeria monocytogenes (PTHP_LISMO), Staphylococcus carnosus, Sta. aureus (PTHP_STACA), Streptococcus mutans, Str. salivarius (PTHP_STRMU), Ent. faecalis (PTHP_ENTFA), Mycoplasma capricolum (PTHP_MYCCA), M. pneumoniae, M. genitalium (PTHP_MYCPN), Esc. coli, Sal. typhimurium (PTHP_ECOLI), H. influenzae (PTHP_HAEIN), Alcaligenes eutrophus (PTHP_ALCEU); NPr family: NPr from Esc. coli and Klebsiella pneumoniae (PTSO_ECOLI); FPr family: FPr from Esc. coli and Sal. typhimurium (PTFA_ECOLI), H. influenzae (first and second HPr-like domain: PTFA_HAEI1 and PTFA_HAEI2); MTP family: HPr-like domain from Rhodobacter capsulatus (PTF1_RHOCA) and Xanthomonas campestris (PTF1_XANCP). The other sequences were retrieved from complete or incomplete microbial genome sequences available on the NCBI website (http://www.ncbi.nlm.nih.gov/BLAST/index.html) by using the TBLASTN program (Altschul et al., 1997) and Crh as the query sequence. Preliminary genome sequence data were obtained from the website of The Institute for Genomic Research (http://www.tigr.org). Incomplete microbial genomes: Caulobacter crescentus (two occurrences), N. meningitidis, N. gonorrhoeae, Bor. pertussis, P. aeruginosa, Chl. tepidum, Clostridium acetobutylicum and complete genome: T. pallidum.

bium tepidum, Pseudomonas aeruginosa, Neisseria gonorrhoeae, Neisseria meningitidis and Treponema pallidum. Interestingly, the HPrs of these organisms are most closely related to Crh (Fig. 2). Although belonging to the Gram-negative bacteria, several of these organisms including T.pallidum, C. tepidum, Bor.pertussis, $N$. meningitidis and N. gonorrhoeae were found to contain a homologue of the bifunctional enzyme $\mathrm{HPr}$ kinase/P-Ser-HPr phosphatase (Galinier et al., 1998; Reizer et al., 1998; Kravanja et al., 1999), suggesting that HPr of these Gram-negative organisms might also be phosphorylated at Ser-46. On the unrooted phylogenetic tree (Fig. 2), most Gram-positive HPrs are clustered and this is also true for several Gram-negative HPrs (E. coli, H. influenzae), whereas the other proteins including Crh and its closest relatives are all branched at the same node or very close to this node. This type of tree suggests that the proteins exhibiting the strongest sequence similarity to Crh do not constitute a homogeneous family but are intermediate between HPrs from Gram-positive and Gram-negative bacteria.

\section{Mutation of ptsH and/or crh does not cause noticeable changes in the overall protein-synthesis pattern}

Two-dimensional gel electrophoresis experiments were carried out with crude extracts prepared from the $B$. subtilis wild-type strain $168\left(p t s H^{+} c r b^{+}\right)$, the two single mutants GM1341 ( $\left.p t s H^{-}\right)$and CRH168 $\left(c r b^{-}\right)$as well as 


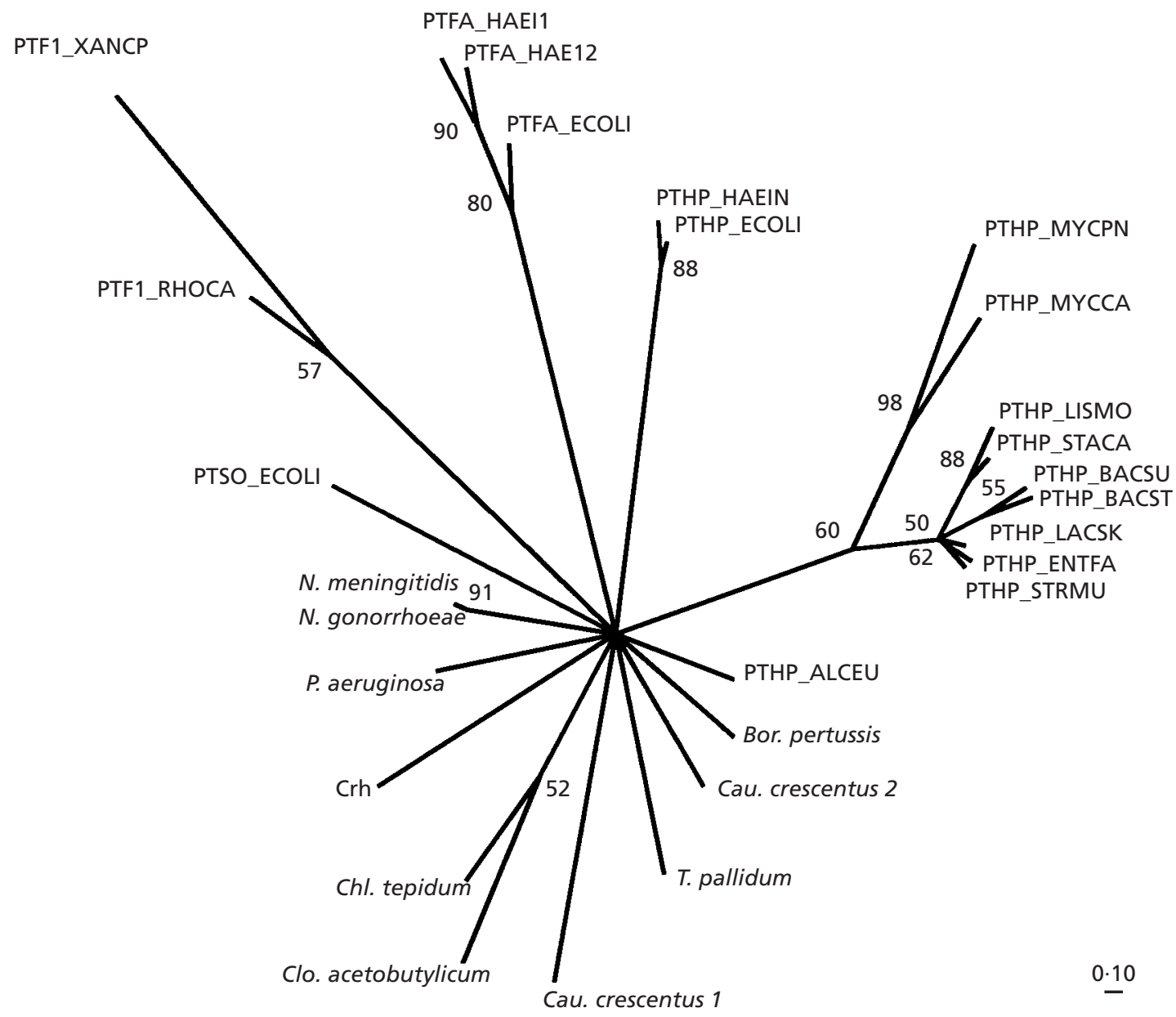

Fig. 2. Unrooted tree showing the evolutionary relatedness of HPr and HPr-like proteins from various bacteria. The branch length is proportional to the relative evolutionary distance. The tree has been constructed with PUZzLE (Strimmer \& von Haeseler, 1996), a program based on maximum likelihood, that gives a statistical estimation of each internal branch (numbers at nodes). We used the JTT models of substitution with a rate heterogeneity modelled by a discrete gamma distribution with 4 categories (abbreviations are as indicated in Fig. 1).

from the $p t s H$ crh double mutant HC1341. Compared to the wild-type strain, no drastic changes of the protein synthesis pattern in the double or the two single mutants were observed (data not shown), suggesting that neither $\mathrm{HPr}$ nor Crh exerts a strong influence on gene expression when cells are grown in rich medium in the absence of carbohydrates. The migration position of HPr from $B$. subtilis 168 has been determined as described under Methods. However, a spot migrating to the position of HPr was present not only in the $c r h$ mutant CRH168, but also in the pts $H$ mutant GM1341 carrying a 108 bp in-frame deletion from codon 7 to 42 in $p t s H$ (Tortosa et al., 1997) (data not shown). This protein spot disappeared only in the ptsH crh double mutant HC1341, suggesting that although $\mathrm{Crh}$ and $\mathrm{HPr}$ of $B$. subtilis exhibit only $45 \%$ sequence identity, the two proteins migrate to exactly the same position during twodimensional gel electrophoresis. This assumption was confirmed by carrying out mass spectrometry with tryptic fragments derived from the corresponding pro- tein spot obtained from strain CRH168, which was found to represent $\mathrm{HPr}$, and from strain GM1341, which was identified as Crh. This finding is in agreement with the very similar molecular mass and $\mathrm{pI}$ values calculated for these two proteins (pI 4.86 and 4.9 , and molecular mass $9058 \mathrm{Da}$ and $9327 \mathrm{Da}$ for $\mathrm{HPr}$ and Crh, respectively). The protein spots corresponding to $\mathrm{Crh}$ in strain GM1341 and to HPr in strain CRH168 were of similar intensity, suggesting that similar amounts of $\mathrm{HPr}$ and Crh are present in the cell.

\section{Q15H mutant Crh can be phosphorylated by enzyme $I$ and PEP}

His-15 is the site of PEP-dependent enzyme I-catalysed phosphorylation of HPr. In Crh, His-15 was found to be replaced with a glutamine and no PEP-dependent, enzyme I-catalysed phosphorylation of wild-type Crh was detected (Galinier et al., 1997). We wanted to test whether replacement of Gln-15 of Crh with a histidyl 


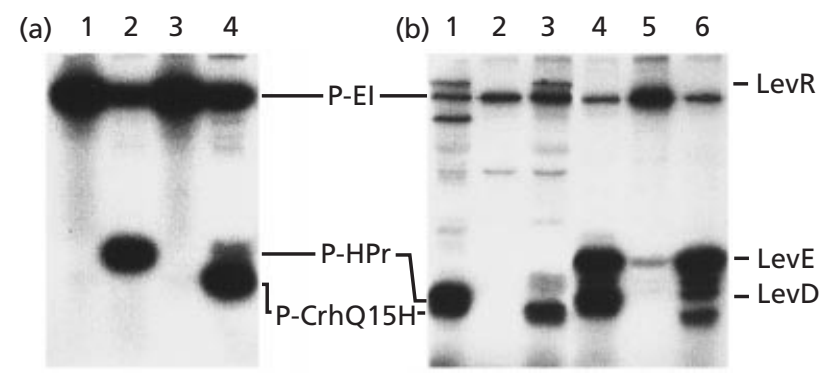

Fig. 3. In vitro PEP-dependent enzyme l-catalysed phosphorylation of $\mathrm{HPr}$, Crh and Q15H mutant Crh. Phosphorylation of the various proteins was carried out as described in Methods. (a) Autoradiogram obtained from a $15 \%$ SDS-PAGE gel on which samples containing the following proteins had been loaded: lane 1, enzyme I(His) $)_{6}$; lane 2, enzyme $\mathrm{I}(\mathrm{His})_{6}$ and $\mathrm{HPr}(\mathrm{His})_{6}$; lane 3, enzyme $\mathrm{I}(\mathrm{His})_{6}$ and wildtype $\mathrm{Crh}(\mathrm{His})_{6}$; lane 4, enzyme I(His) 6 and $\mathrm{CrhQ15H}(\mathrm{His})_{6}$. (b) Autoradiogram obtained from a $12.5 \%$ SDS-PAGE gel on which samples containing the following proteins had been loaded: lane 1, enzyme I(His) ${ }_{6}, \mathrm{HPr}(\mathrm{His})_{6}$ and LevR; lane 2, enzyme I(His) ${ }_{6}$, wild-type $\mathrm{Crh}(\mathrm{His})_{6}$ and LevR; lane 3, enzyme I(His) ${ }_{6}$ CrhQ15H(His) ${ }_{6}$ and LevR; lane 4, enzyme I(His) $)_{6}, \mathrm{HPr}(\mathrm{His})_{6}$, LevD(His) ${ }_{6}$ and LevE(His) ${ }_{6}$; lane 5, enzyme I(His) ${ }_{6}$, wild-type $\left.\mathrm{Crh}(\mathrm{His})_{6}, \mathrm{LevD}_{\mathrm{His}}\right)_{6}$ and $\operatorname{LevE}(\mathrm{His})_{6}$; lane 6, enzyme I(His) CrhQ15H(His) $)_{6}$ LevD(His) 6 and LevE(His) ${ }_{6}$.

residue would allow PEP-dependent enzyme I-catalysed phosphorylation of the mutant protein. A mutation exchanging Gln-15 for histidine was introduced into $\mathrm{crh}$, the $\mathrm{crhQ15H}$ allele was inserted into a His-tag expression vector and His-tagged CrhQ15H was purified as described in Methods. PEP-dependent phosphorylation experiments were carried out with enzyme I and $\mathrm{HPr}$, Crh or CrhQ15H. As previously reported (Galinier et al., 1997), no PEP-dependent phosphorylation was observed for wild-type Crh (Fig. 3a, lane 3). However, under the experimental conditions employed, the Q15H mutant Crh was found to be phosphorylated to a similar extent as HPr (Fig. 3a, lanes 2 and 4). In contrast to wild-type HPr and Crh, the two His-tagged proteins were found to migrate to slightly different positions during SDS-PAGE. This is probably due to the different composition and location of the His-tag in $\mathrm{HPr}$ and Crh (see Methods section).

\section{Q15H mutant Crh does not restore growth of the pts $H \Delta$ DH strain on PTS sugars and glycerol}

To find out whether CrhQ15H can replace HPr as phosphoryl carrier in PTS-catalysed sugar uptake, we tested whether a $p t s H$ deletion strain producing Crh$\mathrm{Q} 15 \mathrm{H}$ would be able to grow in minimal medium containing $1 \mathrm{mM}$ IPTG (for induction of the $c r h$ allele under the control of the spac promoter) and $0.5 \%$ of glucose, fructose, mannitol, glycerol or glucitol. Compared to the wild-type strain, the $p t s H$ deletion strain QB7111 exhibited drastically increased doubling times when grown in the presence of the PTS sugars glucose, fructose or mannitol or the non-PTS sugar glycerol, whereas growth in the presence of glucitol was slowed only slightly (Table 1). Expression of the $\mathrm{crbQ15H}$ allele from the spac promoter in strain QB7114 had no detectable influence on its growth behaviour, indicating that, when integrated as a single copy into amyE, the crhQ15H allele is not capable of restoring the uptake of the PTS sugars glucose, fructose or mannitol or the PHis-HPr-activated catabolism of glycerol (Deutscher et al., 1993; Charrier et al., 1997b). To test the effect of $c r h$ or crhQ15H expression from a multicopy plasmid on the growth behaviour of a $\Delta p t s H$ strain, QB7111 was transformed with pRC19 or pRC20, $c r h-$ or $c r h Q 15 H-$ carrying derivatives, respectively, of the multicopy plasmid pHT315 (Arantes \& Lereclus, 1991). Similar to strain QB7114, which contains the crhQ15H allele integrated into $a m y E$, the resulting transformants grew very slowly on minimal medium containing either glucose, fructose, mannitol or glycerol as the sole carbon source (data not shown), although the amount of Crh present in the cells transformed with plasmids pRC19 or pRC20 was found to be clearly elevated compared to the amount of Crh present in cells containing the crh allele in single copy. The amount of $\mathrm{Crh}$ in the various transformants and integrants was quantified by carrying out Western blots with crude extracts using rabbit polyclonal antibodies directed against $B$. subtilis $\mathrm{Crh}$ (data not shown).

\section{CrhQ15H can phosphorylate LevD and LevR}

To test whether CrhQ15H is capable of restoring other catalytic and regulatory functions carried out by P-His$\mathrm{HPr}$, we investigated whether it can phosphorylate the transcriptional activator LevR (Martin-Verstraete et al., 1998) and catalyse the LevD-mediated phosphorylation of LevE, a fructose-specific enzyme IIB (Charrier et al., 1997a). LevR and LevD have been demonstrated to be phosphorylated by P-His-HPr (Charrier et al., 1997a) (see also Fig. 3b, lanes 1 and 4). In the presence of wild-type Crh, no phosphorylation of LevR and of LevD/LevE was observed (Fig. 3b, lanes 2 and 5). The weak radioactive band migrating to the position of LevE in Fig. 3 (b), lane 5 is probably due to a contamination of LevD, since it was also observed when the phosphorylation mixture did not contain LevE (data not shown). However, LevR, LevD and LevE became clearly phosphorylated when Crh was replaced with CrhQ15H in the phosphorylation assay (Fig. 3b, lanes 3 and 6). Since the amount of LevE present in the phosphorylation assay was 10 -fold higher than the amount of LevD, the phosphoryl group was mainly transferred to LevE (Fig. 3 b, lane 6). The predominant phosphorylation of LevE suggests that, identical to the phosphorylation in the presence of HPr (Charrier et al., 1997a), LevD is probably intermediately phosphorylated at His-9 in the presence of CrhQ15H and the phosphoryl group is subsequently transferred from phosphorylated LevD to His-15 in LevE. In contrast, although glycerol kinase from Enterococcus casseliflavus was found to be phosphorylated by HPr at a single histidyl residue (Charrier et al., 1997b), no phosphorylation of this protein was detected in the presence of CrhQ15H (data not shown). 
Table 1. Doubling time of $B$. subtilis 168 and a pts $H \Delta \mathrm{DH}$ strain with and without the $c r h Q 15 H$ allele integrated at the amyE locus

\begin{tabular}{|c|c|c|c|c|c|c|}
\hline \multirow[t]{2}{*}{ Strain } & \multirow{2}{*}{$\begin{array}{l}\text { Relevant } \\
\text { Genotype }\end{array}$} & \multicolumn{5}{|c|}{ Doubling time ( $\mathrm{min}$ ) in C medium supplemented with: } \\
\hline & & Glucose & Fructose & Mannitol & Glycerol & Glucitol \\
\hline QB5030 & $p t s H^{+}$ & 75 & 90 & 95 & 96 & 100 \\
\hline QB7111 & $p t s H \Delta \mathrm{DH}$ & 400 & $>600$ & $>600$ & $>600$ & 132 \\
\hline QB7114 & $\begin{array}{l}\text { pts } H \Delta \mathrm{DH} \\
\text { pspac crhQ15H }\end{array}$ & 400 & $>600$ & $>600$ & $>600$ & 130 \\
\hline
\end{tabular}

Table 2. Expression of a sac $C^{\prime}::$ lacZ fusion in a $p t s H \Delta D H$ strain in the presence and absence of CrhQ15H

\begin{tabular}{|c|c|c|c|}
\hline \multirow[t]{2}{*}{ Strain } & \multirow[t]{2}{*}{ Relevant Genotype } & \multicolumn{2}{|c|}{$\beta$-Galactosidase activity [Units $\left.(\mathrm{mg} \text { protein })^{-1}\right]$} \\
\hline & & CSK & CSK + fructose \\
\hline QB7111 & $\begin{array}{c}p t s H \Delta \mathrm{DH} \\
s a c C^{\prime}:: l a c Z^{+}\end{array}$ & 470 & 415 \\
\hline QB7114 & $\begin{array}{c}p t s H \Delta \mathrm{DH} \\
\text { pspac crhQ15H } \\
\text { sac }^{\prime}:: \mathrm{lacZ}^{+}\end{array}$ & 6 & 953 \\
\hline
\end{tabular}

\section{Constitutive expression from the lev promoter in the pts $\Delta \Delta \mathrm{DH}$ strain becomes fructose-inducible when CrhQ15H is synthesized}

In addition to phosphorylation of LevR at His-585 by enzyme I and $\operatorname{HPr}$ (Fig. 3b, lane 1), which stimulates its transcriptional activator activity, LevR was also found to be phosphorylated via enzyme I, HPr, LevD and LevE at His-869. This second phosphorylation inactivates LevR and occurs when fructose or mannose, the substrates of the lev-PTS, are absent from the growth medium. In the presence of one of its substrates, the components of the lev-PTS and consequently also His869 of LevR are thought to become dephosphorylated leading to activation of LevR and to induction of the lev operon. In agreement with this concept, replacement of His-869 with alanine (Martin-Verstraete et al., 1998) or mutations inactivating enzyme I, HPr, LevD or LevE (Martin-Verstraete et al., 1990, 1995; Stülke et al., 1995) led to constitutive expression from the lev promoter. We wanted to test whether the synthesis of $\mathrm{CrhQ} 15 \mathrm{H}$ would allow phosphorylation of LevR at His-869 and thus make the constitutive expression from the lev promoter in a $p t s H$ deletion strain fructose-inducible. When grown in the absence of a sugar, the ptsH deletion strain QB7111 exhibited constitutive expression of a sac $C^{\prime}$ : : lac Z fusion (Table 2). The sacC gene encodes the enzyme levanase and is the fifth and last gene in the lev operon (Martin-Verstraete et al., 1990). A similarly high $\beta$-galactosidase activity was measured when the cells were grown in the presence of fructose. In contrast, the $p t s H$ deletion strain QB7114 in which the crhQ15H mutant allele was integrated into amyE and expressed from the spac promoter exhibited very low $\beta$-galactosidase activity in the absence of fructose. $\beta$-Galactosidase activity was more than 150-fold higher when strain QB7114 was grown in fructose-containing medium (Table 2), indicating that in the presence of CrhQ15H, LevR is inactivated by PEP-dependent phosphorylation catalysed by enzyme I, CrhQ15H, LevD and LevE. Similar to that observed for a $p t s H^{+}$strain (MartinVerstraete et al., 1990), expression from the lev promoter in QB7114 was fructose-inducible, as the uptake of fructose via the lev-PTS probably leads to dephosphorylation and activation of LevR.

\section{DISCUSSION}

Crh exhibits not only $45 \%$ sequence identity to HPr of $B$. subtilis and migrates to the same position during twodimensional gel electrophoresis, it can also be phosphorylated by ATP and the HPr kinase at Ser-46 and, when Gln-15 is replaced with a histidine, by PEP and enzyme I at His-15. Similar to P-Ser-HPr, P-Ser-Crh was found to act as corepressor for CcpA during carboncatabolite repression and catabolite activation (Galinier et al., 1997; Turinsky et al., 1998; Zalieckas et al., 1998; Galinier et al., 1999; Martin-Verstraete et al., 1999). These results suggest that the structure of Crh strongly resembles that of HPr proteins. Separation of crude extracts from B. subtilis GM1341 ( $p t s H$ deletion) and CRH168 (crh disruption) on two-dimensional gels and identification of the spots representing $\mathrm{HPr}$ and $\mathrm{Crh}$ suggested that the two proteins $\mathrm{HPr}$ and Crh are 
synthesized in similar amounts. However, expression of the gene encoding $\mathrm{CrhQ} 15 \mathrm{H}$ in a $p t s H$ deletion strain did not restore growth on the PTS sugars glucose, fructose and mannitol, neither when expressed as single copy after integration into amyE, nor when expressed from a multicopy plasmid. Starting from a $p t s H$ deletion strain transformed with a plasmid carrying $\mathrm{crhQ15H}$ (pRC20), we tried to obtain spontaneous mutations in $c r h Q 15 H$ allowing growth of the $p t s H \Delta \mathrm{DH}$ strain on mannitol as the sole carbon source. However, our attempts to isolate such crh alleles were not successful. The finding that the N-terminal part of Crh contains certain sequence characteristics found mainly in $\mathrm{HPr}$ from Gram-negative bacteria (Fig. 1) possibly provides an explanation for this failure. The $V_{\max }$ for the PEPdependent phosphorylation at His-15 in HPr from the Gram-negative bacterium E. coli by B. subtilis enzyme I was found to be 20 -fold lower compared to the $V_{\max }$ determined for the phosphorylation reaction with the two B. subtilis proteins (Reizer et al., 1992b). To make the PEP-dependent phosphorylation site of CrhQ15H more closely resemble the phosphorylation site in Grampositive $\mathrm{HPr}$, more than one mutation in addition to the already present $\mathrm{Q} 15 \mathrm{H}$ exchange (see Fig. 1) may be required.

Nevertheless, P-His-CrhQ15H was capable of efficiently phosphorylating the transcriptional regulator LevR. LevR has been shown to be phosphorylated by HPr at His-585 and this phosphorylation was suggested to play a role in a CcpA-independent CCR mechanism operative for the lev operon (Martin-Verstraete et al., 1998). In addition, P-His-CrhQ15H could phosphorylate LevD, a fructose-specific enzyme IIA, and the phosphoryl group was subsequently transferred from phosphorylated LevD to LevE, a fructose-specific enzyme IIB. This phosphorylation cascade fulfils two functions. First, it is used for lev-PTS catalysed uptake of fructose (Charrier et al., 1997a). However, fructose uptake via the lev-PTS is very slow (Gay \& Delobbe, 1973; Martin-Verstraete et al., 1990). Although the lev-PTS is fully active in fruA or fruB mutants, which are defective in enzyme IIA ${ }^{\text {Fru }}$ or phosphofructokinase 1 , respectively, two components of the main fructose metabolic pathway in B. subtilis, doubling times exceeding $360 \mathrm{~min}$ have been reported for these mutants when they were grown on fructose as the sole carbon source (Gay \& Delobbe, 1973). This low fructose-transport activity of the lev-PTS explains why the synthesis of CrhQ15H did not restore growth of a ptsH mutant on fructose (Table 1), although the mutant Crh was found to phosphorylate LevD (Fig. 3, lane 6). In addition, we cannot exclude that the mutant Crh phosphorylates LevD less effectively than HPr, which would further slow fructose uptake via the lev-PTS in the $p t s H$ deletion mutant synthesizing CrhQ15H.

The second function of the enzyme I-HPr-LevD-LevE phosphorylation cascade is phosphorylation of LevR at His-869 (Martin-Verstraete et al., 1998). Phosphorylation of LevR by phosphorylated LevE regulates induction of the lev operon. A ptsH mutant strain, in which the phosphorylation cascade leading to the formation of P-His869-LevR is interrupted, exhibited constitutive expression from the lev promoter (MartinVerstraete et al., 1998). Expression of the gene encoding CrhQ15H in a $\Delta p t s H$ mutant allowed reconstitution of the phosphorylation cascade from enzyme I to LevD to LevE and finally LevR, which prevented the constitutive expression from the lev promoter observed in the $\Delta p t s H$ mutant and restored its fructose-dependent induction.

Enterococcal glycerol kinases have been shown to be phosphorylated by PEP, enzyme I and HPr at a histidyl residue conserved in glycerol kinases of Gram-positive bacteria; phosphorylation increased glycerol kinase activity about 10-fold (Charrier et al., 1997b). Enterococcus faecalis or B. subtilis mutants defective in enzyme I or HPr therefore have low glycerol kinase activity and cannot grow on media containing glycerol as the sole carbon source (Reizer et al., 1984; Romano et al., 1990; Gonzy-Tréboul et al., 1991). Expression of crhQ15H was not able to restore growth of a $B$. subtilis $p t s H$ deletion strain in the presence of glycerol. This is in agreement with the finding that although B. subtilis $\mathrm{HPr}$ could phosphorylate glycerol kinase from Ent. casseliflavus, no in vitro phosphorylation of this protein was observed in the presence of CrhQ15H. Again, the finding that Crh seems to contain certain characteristics of the PEP-dependent phosphorylation site of HPr from Gramnegative bacteria might explain that $\mathrm{CrhQ} 15 \mathrm{H}$ is able to phosphorylate LevR, but not glycerol kinase. PEPdependent phosphorylation of glycerol kinase has been observed only in Gram-positive bacteria (Charrier et al., 1997b). In contrast, proteins containing the PTS regulation domain, which carries the site of P-His-HPr dependent phosphorylaton of LevR, have also been detected in Esc. coli and other Gram-negative bacteria (Stülke et al., 1998).

In summary, the results presented here show that $\mathrm{Crh}$ in which Gln-15 has been replaced with a histidine is capable of carrying out some of the regulatory functions of $\mathrm{HPr}$ (phosphorylation of the transcriptional activator LevR at His-585 and His-869). The observed PEPdependent enzyme I-catalysed phosphorylation of LevD/LevE in the presence of CrhQ15H suggests that CrhQ15H might be able to catalyse slow transport of fructose via the lev-PTS. However, the transport function for the most important PTS sugars glucose, fructose (via FruA) and mannitol as well as the P-His-HPrdependent activation of glycerol catabolism could not be restored by the presence of CrhQ15H.

\section{ACKNOWLEDGEMENTS}

This research was supported by the Ministère de l'Education Nationale de la Recherche et de la Technologie, the Centre National de la Recherche Scientifique, the Institut National Agronomique, the Institut Pasteur, the Université Lyon I, the Universite Paris 7 and the European Community BIOTECH programme contract number BIO4-CT96-0380. Sequence data from incomplete bacterial genomes were obtained from The Institute for Genomic Research through the website (http://www.tigr.org). Sequencing of the genome of Caulobacter crescentus, Chlorobium tepidum and N. meningitidis 
was supported by DEO and Wellcome Trust. We are thankful to W. Hengstenberg for providing B. subtilis HPr without Histag, to A. Guiseppi for constructing strains CRH168 and HC1341, to J.-P. Lecaer for mass spectrometry and to C. van Herrewege and A. Bosch for their expert assistance during preparation of this manuscript.

\section{REFERENCES}

Altschul, S. F., Madden, T. L., Schaffer, A. A., Zhang, J., Zhang, Z., Miller, W. \& Lipman, D. J. (1997). Gapped BLAST and PSI-BLAST: a new generation of protein database search programs. Nucleic Acids Res 25, 3389-3402.

Arantes, O. \& Lereclus, D. (1991). Construction of cloning vectors for Bacillus thuringiensis. Gene 108, 115-119.

Charrier, V., Deutscher, J., Galinier, A. \& Martin-Verstraete, I. (1997a). Protein phosphorylation chain of a Bacillus subtilis fructose-specific phosphotransferase system and its participation in regulation of the expression of the lev operon. Biochemistry 36 , 1163-1172.

Charrier, V., Buckley, E., Parsonage, D., Galinier, A., Darbon, E., Jaquinod, M., Forest, E., Deutscher, J. \& Claiborne, A. (1997b). Cloning and sequencing of two enterococcal $g l p K$ genes and regulation of the encoded glycerol kinases by phosphoenolpyruvate-dependent, phosphotransferase system-catalyzed phosphorylation of a single histidyl residue. J Biol Chem 272, 14166-14174.

Cortay, J. C., Nègre, D., Scarabel, M., Ramseier, T., Vartak, N. B., Reizer, J., Saier, M. H., Jr \& Cozzone, A. J. (1994). In vitro asymmetric binding of the pleiotropic regulatory protein, FruR, to the ace operator controlling glyoxylate shunt enzyme synthesis. J Biol Chem 269, 14885-14891.

Deutscher, J. \& Saier, M. H., Jr (1983). ATP-dependent protein kinase-catalyzed phosphorylation of a seryl residue in HPr, a phosphate carrier protein of the phosphotransferase system in Streptococcus pyogenes. Proc Natl Acad Sci USA 80, 6790-6794.

Deutscher, J., Bauer, B. \& Sauerwald, H. (1993). Regulation of glycerol metabolism in Enterococcus faecalis by phosphoenolpyruvate-dependent phosphorylation of glycerol kinase catalyzed by Enzyme I and HPr of the phosphotransferase system. J Bacteriol 175, 3730-3733.

Deutscher, J., Küster, E., Bergstedt, U., Charrier, V. \& Hillen, W. (1995). Protein kinase-dependent $\mathrm{HPr} / \mathrm{CcpA}$ interaction links glycolytic activity to carbon-catabolite repression in Grampositive bacteria. Mol Microbiol 15, 1049-1053.

Du, Y., Holtel, A., Reizer, J. \& Saier, M. H., Jr (1996). Sigma54dependent transcription of the Pseudomonas putida $x y l S$ operon is influenced by the IIA $^{\mathrm{Ntr}}$ protein of the phosphotransferase system in Escherichia coli. Res Microbiol 147, 129-132.

Fujita, Y., Miwa, Y., Galinier, A. \& Deutscher, J. (1995). Specific recognition of the Bacillus subtilis gnt cis-acting cataboliteresponsive element by a protein complex formed between CcpA and seryl-phosphorylated HPr. Mol Microbiol 17, 953-960.

Galinier, A., Haiech, J., Kilhoffer, M.-C., Jaquinod, M., Stülke, J., Deutscher, J. \& Martin-Verstraete, I. (1997). The Bacillus subtilis crh gene encodes a HPr-like protein involved in carbon-catabolite repression. Proc Natl Acad Sci USA 94, 8439-8444.

Galinier, A., Kravanja, M., Engelmann, R., Hengstenberg, W., Kilhoffer, M.-C., Deutscher, J. \& Haiech, J. (1998). New protein kinase and protein phosphatase families mediate signal transduction in bacterial catabolite repression. Proc Natl Acad Sci USA 95, 1823-1828.

Galinier, A., Deutscher, J. \& Martin-Verstraete, I. (1999). Phos- phorylation of either Crh or HPr mediates binding of CcpA to the Bacillus subtilis xyn cre and catabolite repression of the $x y n$ operon. J Mol Biol 286, 307-314.

Galtier, N., Gouy, M. \& Gautier, C. (1996). SEAVIEW and PHYLO_ WIN : two graphic tools for sequence alignment and molecular phylogeny. Comput Appl Biosci 12, 543-548.

Gay, P. \& Delobbe, A. (1973). Fructose transport in Bacillus subtilis. Eur J Biochem 79, 363-373.

Geerse, R. H., Izzo, F. \& Postma, P. W. (1989). The PEP : fructose phosphotransferase system in Salmonella typhimurium: FPr combines enzyme III ${ }^{\mathrm{Fru}}$ and pseudo-HPr activities. Mol Gen Genet 216, 517-525.

Gonzy-Tréboul, G., de Waard, J. H., Zagorec, M. \& Postma, P. W. (1991). The glucose permease of the phosphotransferase system of Bacillus subtilis: evidence for $\mathrm{II}^{\mathrm{Glc}}$ and $\mathrm{III}^{\mathrm{Gle}}$ domains. Mol Microbiol 5, 1241-1249.

Gösseringer, R., Küster, E., Galinier, A., Deutscher, J. \& Hillen, W. (1997). Cooperative and non-cooperative DNA binding modes of catabolite control protein CcpA from Bacillus megaterium result from sensing two different signals. J Mol Biol 266, 665-676.

Henkin, T. M., Grundy, F. J., Nicholson, W. L. \& Chambliss, G. H. (1991). Catabolite repression of $\alpha$-amylase gene expression in Bacillus subtilis involves a transacting gene product homologous to the Escherichia coli lacI and galR repressors. Mol Microbiol 5, 575-584.

Hueck, C. J., Hillen, W. \& Saier, M. H., Jr (1994). Analysis of a cisactive sequence mediating catabolite repression in Gram-positive bacteria. Res Microbiol 145, 503-518.

Ireton, K., Rudner, D. Z., Siranosian, K. J. \& Grossman, A. D. (1993). Integration of multiple developmental signals in Bacillus subtilis through the Spo0A transcription factor. Genes Dev 7, 283-294.

Jones, D. H. A., Franklin, C. H. \& Thomas, C. M. (1994). Molecular analysis of the operon which encodes the RNA polymerase sigma factor $\sigma 54$ of Escherichia coli. Microbiology 140, 1035-1043.

Kim, J. H., Voskuil, M. I. \& Chambliss, G. H. (1998). NADP, corepressor for the Bacillus catabolite control protein CcpA. Proc Natl Acad Sci USA 95, 9590-9595.

Kravanja, M., Engelmann, R., Dossonnet, V., Blüggel, M., Meyer, H. E., Frank, R., Galinier, A., Deutscher, J. \& Hengstenberg, W. (1999). The hprK gene of Enterococcus faecalis encodes a novel bifunctional enzyme: the HPr kinase/phosphatase. Mol Microbiol 31, 59-66.

Kunst, F. \& Rapoport, G. (1995). Salt stress is an environmental signal affecting degradative enzyme synthesis in Bacillus subtilis. J Bacteriol 177, 2403-2407.

Kunst, F., Ogasawara, N., Moszer, I. \& 148 other authors (1997). The complete genome sequence of the Gram-positive bacterium Bacillus subtilis. Nature 390, 249-256.

Laemmli, U. K. (1970). Cleavage of structural proteins during the assembly of the head of bacteriophage T4. Nature 227, 680-685.

Martin-Verstraete, I., Débarbouillé, M., Klier, A. \& Rapoport, G. (1990). Levanase operon of Bacillus subtilis includes a fructosespecific phosphotransferase system regulating the expression of the operon. J Mol Biol 214, 657-671.

Martin-Verstraete, I., Stülke, J., Klier, A. \& Rapoport, G. (1995). Two different mechanisms mediate catabolite repression of the Bacillus subtilis levanase operon. J Bacteriol 177, 6919-6927.

Martin-Verstraete, I., Charrier, V., Stülke, J., Galinier, A., Erni, B., Rapoport, G. \& Deutscher, J. (1998). Antagonistic effects of dual PTS-catalysed phosphorylation on the Bacillus subtilis transcriptional activator LevR. Mol Microbiol 28, 293-303. 
Martin-Verstraete, I., Deutscher, J. \& Galinier, A. (1999). Phosphorylation of $\mathrm{HPr}$ and Crh, early steps in the catabolite repression signalling pathway for the Bacillus subtilis levanase operon. J Bacteriol 181, 2966-2969.

Miller, J. H. (1972). Experiments in Molecular Genetics. Cold Spring Harbor, NY: Cold Spring Harbor Laboratory.

Postma, P. W., Lengeler, J. W. \& Jacobson, G. R. (1993). Phosphoenolpyruvate:carbohydrate phosphotransferase systems of bacteria. Microbiol Rev 57, 543-594.

Powell, B. S., Court, D. L., Inada, T., Nakamura, Y., Michotey, V., Cui, X., Reizer, A., Saier, M. H., Jr \& Reizer, J. (1995). Novel proteins of the phosphotransferase system encoded within the rpoN operon of Escherichia coli: enzyme IIA ${ }^{\mathrm{Ntr}}$ affects growth on organic nitrogen and the conditional lethality of an $\mathrm{era}^{\text {ts }}$ mutant. J Biol Chem 270, 4822-4839.

Reizer, J., Novotny, M. J., Stuiver, I. \& Saier, M. H., Jr (1984). Regulation of glycerol uptake by the phosphoenolpyruvate-sugar phosphotransferase system in Bacillus subtilis. J Bacteriol 159, 243-250.

Reizer, J., Reizer, A. \& Saier, M. H., Jr (1992a). A proposed link between nitrogen and carbon metabolism involving protein phosphorylation in bacteria. Protein Sci 1, 722-726.

Reizer, J., Sutrina, S. L., Wu, L.-F., Deutscher, J., Reddy, P. \& Saier, M. H., Jr (1992b). Functional interactions between proteins of the phosphoenolpyruvate:sugar phosphotransferase system of Bacillus subtilis and Escherichia coli. J Biol Chem 267, 9158-9169.

Reizer, J., Reizer, A. \& Saier, M. H., Jr (1996). Novel PTS proteins revealed by bacterial genome sequencing: a unique fructosespecific phosphoryl transfer protein with two HPr-like domains in Haemophilus influenzae. Res Microbiol 147, 209-215.

Reizer, J., Hoischen, C., Titgemeyer, F., Rivolta, C., Rabus, R., Stülke, J., Karamata, D., Saier, M. H., Jr \& Hillen, W. (1998). A novel protein kinase that controls carbon-catabolite repression in bacteria. Mol Microbiol 27, 1157-1169.

Romano, A. H., Saier, M. H., Jr, Harriott, O. T. \& Reizer, J. (1990). Physiological studies on regulation of glycerol utilization by the phosphoenolpyruvate: sugar phosphotransferase system in Enterococcus faecalis. J Bacteriol 172, 6741-6748.

Roossien, F. F., Brink, J. \& Robillard, G. T. (1983). A simple procedure for the synthesis of $\left[{ }^{32} \mathrm{P}\right]$ phosphoenolpyruvate via the pyruvate kinase exchange reaction at equilibrium. Biochim Biophys Acta 760, 185-187.
Saier, M. H., Jr \& Reizer, J. (1992). Proposed uniform nomenclature for the proteins and protein domains of the bacterial phosphoenolpyruvate: sugar phosphotransferase system. J Bacteriol 174, 1433-1438.

Sambrook, J., Fritsch, E. F. \& Maniatis, T. (1989). Molecular Cloning: a Laboratory Manual, 2nd edn. Cold Spring Harbor, NY : Cold Spring Harbor Laboratory.

Strimmer, K. \& von Haeseler, A. (1996). Quartet puzzling: a quartet maximum likelihood method for reconstructing tree topologies. Mol Biol Evol 13, 964-969.

Stülke, J., Martin-Verstraete, I., Charrier, V., Klier, A., Deutscher, J. \& Rapoport, G. (1995). The HPr protein of the phosphotransferase system links induction and catabolite repression of the Bacillus subtilis levanase operon. J Bacteriol 177, 6928-6936.

Stülke, J., Arnaud, M., Rapoport, G. \& Martin-Verstraete, I. (1998). PRD - a protein domain involved in PTS-dependent induction and carbon-catabolite repression of catabolic operons in bacteria. Mol Microbiol 28, 865-874.

Tortosa, P., Aymerich, S., Lindner, C., Saier, M. H., Jr, Reizer, J. \& Le Coq, D. (1997). Multiple phosphorylation of SacY, a Bacillus subtilis transcriptional antiterminator negatively controlled by the phosphotransferase system. J Biol Chem 272, 17230-17237.

Turinsky, A. J., Grundy, F. J., Kim, J. H., Chambliss, G. H. \& Henkin, T. M. (1998). Transcriptional activation of the Bacillus subtilis ack $A$ gene requires sequences upstream of the promoter. J Bacteriol 180, 5961-5967.

Vagner, V., Dervyn, E. \& Ehrlich, S. D. (1998). A vector for systematic gene inactivation in Bacillus subtilis. Microbiology 144, 3097-3104.

Waygood, E. B., Mattoo, R. L. \& Peri, K. G. (1984). Phosphoproteins and the phosphoenolpyruvate: sugar phosphotransferase system in Salmonella typhimurium and Escherichia coli: evidence for III $^{\text {Mannose }}$, III ${ }^{\text {Fructose }}$, III ${ }^{\text {Glucitol}}$, and the phosphorylation of enzyme II ${ }^{\text {Mannitol }}$ and enzyme II $^{N \text {-acetylglucosamine }}$. J Cell Biochem 25, 139-159.

Zalieckas, J. M., Wray, L. V. \& Fisher, S. H. (1998). Expression of the Bacillus subtilis acsA gene: position and sequence context affect cre-mediated carbon-catabolite repression. J Bacteriol 180, 6649-6654.

Received 19 April 1999; revised 2 July 1999; accepted 9 July 1999. 